\title{
Evolução e Potencialidades de Inovação do Turismo de Base Comunitária no Município de Guaraqueçaba - PR (Brasil)
}

\section{Evolution and Innovation Potential of Community-Based Tourism in the Municipality of Guaraqueçaba - PR (Brazil)}

\author{
Thiago Piazzetta Valente (VALENTE, T. P.) ${ }^{*}$ \\ Eduardo Jorge Costa Mielke (MIELKE, E. J. C.) ${ }^{* *}$
}

\begin{abstract}
RESUMO - O presente artigo teve como objetivo avaliar a evolução de uma iniciativa de base comunitária em Guaraqueçaba (Paraná, Brasil), a Cooperguará Ecotur, ao longo de seus 10 anos de atuação em termos do padrão de governança e acesso ao mercado. Além de entrevistas estruturadas, análise de documentos, relatórios, planos de negócio e publicações sobre o tema, a metodologia também incluiu a realização de benchmarking com outras cooperativas de Turismo de Base Comunitária (TBC) no Brasil, para identificar padrões de governança e de acesso ao mercado. Os resultados revelaram haver diversas atividades ainda não exploradas, em especial as voltadas ao turismo de aventura. Por outro lado, a qualidade dos serviços e meios de acesso foram citados como principais dificuldades para operar roteiros turísticos nesse local. Em termos de sua governança, detectou-se que os padrões de tomada de decisão e de acesso ao mercado da Cooperguará Ecotur poderiam ser alvo de melhorias, comparativamente às cooperativas entrevistadas, que revelaram um padrão de governança bastante sólido. $\mathrm{O}$ trabalho em rede e o estabelecimento de vínculos é um passo que deve ser retomado em futuros investimentos no TBC na região.
\end{abstract}

Palavras-chave: Inovação; Governança; Sustentabilidade; Economia; Áreas Protegidas.

ABSTRACT - The present article aimed to evaluate the evolution of a communitybased tourism (CBT) initiative in Guaraqueçaba (Paraná State Coast), the Cooperative Cooperguará Ecotur, that in over its 10 years has been working in terms of governance standard and market access. In addition to structured interviews, analysis of documents, reports, business plans and publications on the subject, the methodology also included benchmarking with other CBT Cooperatives in Brazil, in order to identify governance and market access standards. The results revealed that there are several activities not yet

\footnotetext{
* Formação: Graduação em Biologia pela Universidade Federal do Paraná (UFPR), Especialização em Negócios Ambientais (UFPR) e Mestrado em Agronomia (UFPR). Possui experiência nas áreas de Ecologia com ênfase em botânica aplicada, atuando principalmente nas áreas de ecologia de populações, cadeias produtivas, manejo e conservação de produtos florestais não madeiráveis. Atividade profissional: Fundação Grupo Boticário de Proteção à Natureza, atuando nas áreas de gerenciamento de projetos, análise e planejamento de ações voltadas à conservação de ecossistemas naturais, por meio de ferramentas de Pagamento por Serviços Ambientais (PSA). Endereço físico para correspondência: Rua Gonçalves Dias, 225 - Batel. CEP: 80240-340 - Curitiba - PR - Brasil E-mail: pv.thiago@gmail.com

** Formação: Graduação em Engenharia Agronômica pela UFPR, Mestrado em Ciências Florestais (UFPR), Doutorado em Gestíon y Desarrollo Turístico Sostenible pela Universidad de Málaga (Espanha) e Pós-Doutorado pela Leeds Metropolitan University (Inglaterra). Atividade profissional: Possui expertise em Política de Turismo Municipal, Desenvolvimento Econômico, Cooperativas de Turismo e Turismo de Base Comunitária. É membro do Conselho Nacional de Turismo da CNC. King Abdulaziz University Faculty of Tourism. Kingdom of Saudi Arabia - Jeddah P.O. Box: 80200. Zip Code: 21589. E-mail: emielke@kau.edu.sa
} 
explored, especially those linked to adventure tourism. On the other hand, the quality of services and means of access were cited as the main difficulties to operate tour itineraries in this place. In terms of its governance, it was found that Cooperguará Ecotur standards of decision-making and market access could be improved compared to other Cooperatives interviewed, which revealed a very solid pattern of governance. Networking and connections with others Cooperatives could be a step that must be taken up in future investments in CBT the region.

Key words: Innovation; Governance; Sustainability; Economy; Protected Areas. 


\section{INTRODUÇÃO}

A Floresta Atlântica é um dos biomas de maior integridade ambiental e biodiversidade no Brasil (KAUANO et al., 2012). No estado do Paraná o município de Guaraqueçaba se destaca em representatividade dessa fisionomia. O grau de conservação da região por um lado contribui substancialmente para o repasse de incentivos econômicos diretos para o município, como o ICMS Ecológico (YOUNG et al., 2015), e também cria oportunidades para outros negócios ainda não explorados em termos econômicos a partir de uma perspectiva de negócios e biodiversidade, em especial o turismo. Por outro lado, apesar das contribuições diretas e indiretas que a conservação de sua biodiversidade traz para o município em questão, o seu nível de desenvolvimento econômico ainda pode ser considerado baixo, corroborado por baixos índices de IDH e PIB (BRASIL, 2014), índices que se refletem principalmente no que toca à infraestrutura de acesso e serviços básicos para sua população e também para os que o frequentam.

Em relação ao turismo e sua contribuição, observou-se que embora já exista um mercado e demanda por serviços, principalmente hospedagem, a região de Guaraqueçaba ainda poderia ganhar escala e tornar-se um destino de turismo com demanda constante e alinhada aos objetivos de conservação aos quais foi inicialmente idealizada. Isso provavelmente ainda não ocorreu por diversos fatores e sugere-se que o não estabelecimento de mecanismos eficientes de integração ao mercado de turismo dessa natureza, que operam fortemente em outros estados, como exemplifica o projeto bagagem (PROJETO BAGAGEM, 2010) possa ser o motivo dos entraves existentes para o ganho de escala. Ainda, pode-se perceber que historicamente sempre houve uma lacuna de desenvolvimento de novos serviços, nesse caso focados no turismo, fato essencial para atrair novos públicos que buscam construir experiências junto ao provedor do serviço, focado também em inovação tecnológica (AMEND, 2001; KONU, 2015). Esses aspectos citados muito provavelmente estejam ligados à forma com que as decisões são tomadas visando atender os interesses e dos múltiplos atores, a partir da compreensão do papel de cada um, fenômeno nominado por governança (SILVA, MANTOVANELI JÚNIOR; SAMPAIO, 2014).

Nesse sentido, buscando atuar de maneira inovadora e respeitando a cultura e apoiada nas potencialidades da comunidade local de Guaraqueçaba, estabeleceu-se em 
2006 a Cooperguará Ecotur, uma cooperativa de Turismo de Base Comunitária (TBC) na região. Apoiada por alguns elementos externos estratégicos na sua estruturação (ONGs, Poder Público, Universidades) a Cooperativa conseguiu bons resultados ao longo de 10 anos de existência, embora quase sempre tenha sido acompanhada por instituições e projetos para captação de recursos que pudessem alavancar as suas atividades, fato que pode ter contribuído para um relativo grau de "dependência" externa.

Apesar do cenário favorável, em termos de paisagem e embasamento teórico, verificou-se que o desenvolvimento econômico da região com base no turismo ainda estava carecendo de estruturação estratégica, conforme já exposto. Em uma análise objetiva, detecta-se, que entre os fatores citados como cruciais para o desenvolvimento do turismo comunitário, provavelmente o acesso ao mercado e estabelecimento de parcerias foi o mais crítico e o mais importante a ser desenvolvido. Isso se baseia no pressuposto de que o acesso ao mercado é a condição mais relevante para que o turismo seja viável e ganhe credibilidade junto aos operadores e agências (MIELKE, 2010).

Além da introdução e conclusões, o artigo está estruturado em 2 seções. A primeira trará aspectos relacionados a metodologia empregada na elaboração deste estudo. Já a segunda traz os resultados propriamente ditos com relação aos padrões de governança e acesso ao mercado.

E por fim, o objetivo deste artigo foi avaliar a evolução do Turismo no município de Guaraqueçaba, com enfoque no Turismo de Base Comunitária (TBC), a partir do estudo de caso de uma cooperativa local. Bem como também, evidenciar os principais atrativos existentes atualmente em Guaraqueçaba, o modo de operação e público-alvo; avaliar, por meio do estudo de caso de cooperativa local, a evolução do TBC em termos de governança, engajamento, estabelecimento de parcerias e acesso ao mercado; e por fim também prospectar novos públicos e possibilidades de desenvolvimento de novos produtos.

\section{METODOLOGIA}

O município de Guaraqueçaba está inserido em sua totalidade em uma Área de Proteção Ambiental (APA de Guaraqueçaba) que se sobrepõe a outras unidades de 
conservação de proteção integral, como o Parque Nacional do Superagui, a Estação Ecológica de Guaraqueçaba e a Reserva Biológica de Bom Jesus, além de algumas unidades privadas (RPPNs) como a Reserva Natural Salto Morato e as Reservas do Papagaio-da-Cara-Roxa, ambas administradas por ONGs paranaenses, além da RRPN Sebuí de propriedade privada, segundo dados do portal do Instituto Chico Mendes de Conservação da Biodiversidade (SIMRPPN, 2017). Na Figura 1 é possível observar o mosaico de unidades de conservação, sobrepostas ao município, assim como o elevado grau de cobertura vegetal.

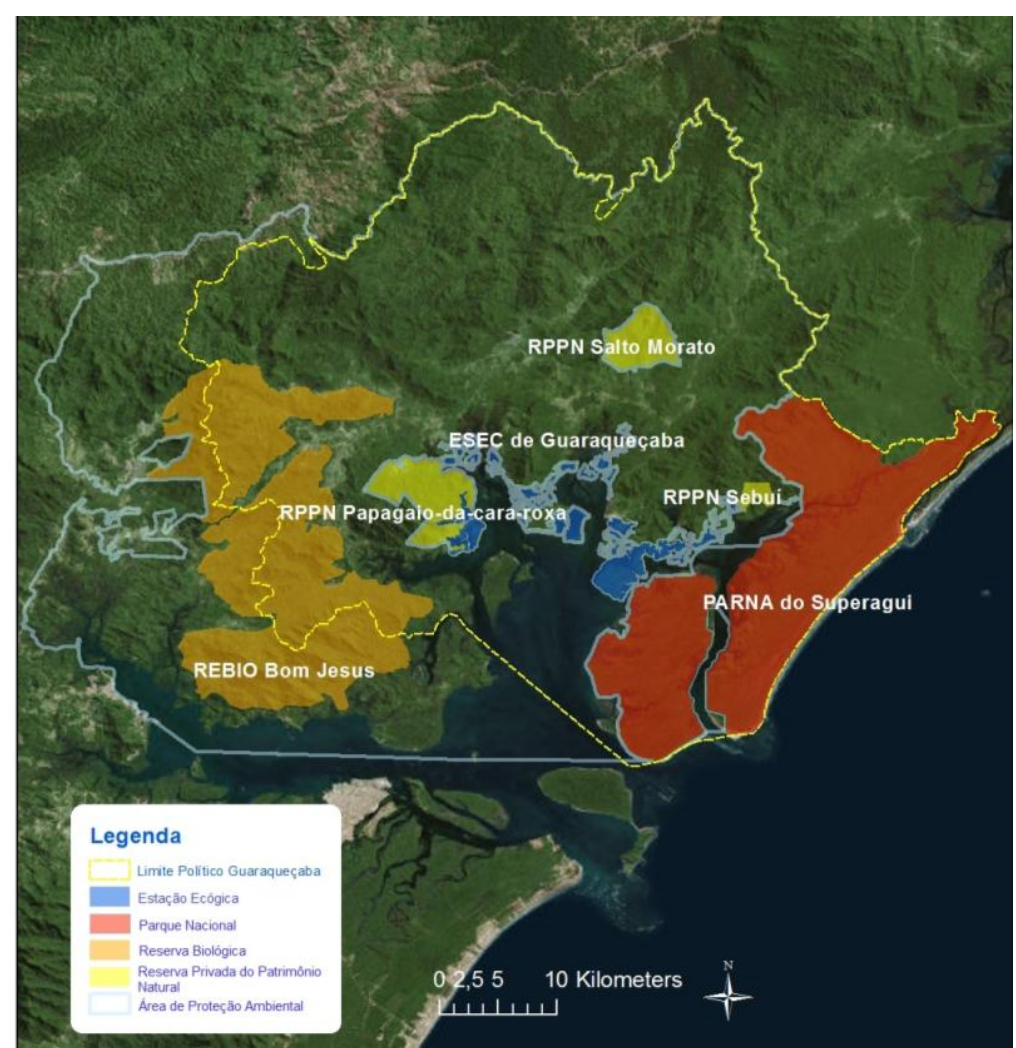

FIGURA 1 - UNIDADES DE CONSERVAÇÃO PRESENTES EM GUARAQUEÇABA - PR E SUAS RESPECTIVAS CATEGORIAS.

FONTE: Acervo Thiago Piazzetta Valente.

O presente trabalho teve como base a análise da evolução do Turismo de Base Comunitária (TBC) em Guaraqueçaba, por meio de entrevistas, leitura de relatórios técnicos e outros materiais disponíveis, além de acompanhamento de atividades relacionadas ao turismo em campo. Buscou-se responder duas questões principais por meio dessa análise:

A) que tratam do modelo de governança adotado pela cooperativa, ou seja, como as decisões foram tomadas e: 
B) como os recursos eram geridos e também como era acesso da cooperativa ao mercado.

A avaliação do acesso ao mercado de turismo pelos prestadores de serviço e residentes em Guaraqueçaba teve uma abordagem qualitativa, assim como se buscou identificar oportunidades de conectar novas frentes de atuação que possam amplificar esse mercado e atrair investimentos no futuro. Para os atores citados, como cooperativas/associações de turismo e agências/operadoras, foi enviado um questionário semiaberto online (utilizando a ferramenta disponível surveymonkey.com) visando investigar as questões de governança e acesso ao mercado. A pesquisa foi disponibilizada online entre junho e agosto de 2016.

Adicionalmente e de forma paralela, foi levada a cabo uma pesquisa exploratória considerando as diversas possibilidades de acesso à informação, buscando novas frentes e possibilidades de ampliação dos serviços turísticos ofertados em Guaraqueçaba. Entre elas pode-se citar o turismo de aventura, que envolve ecoturismo e interpretação. Para avaliar tal efetividade, foram feitos contatos com as principais operadoras de turismo de aventura que operavam na região ou em contextos similares, visando identificar a predisposição em se conectar com atividades/roteiros em Guaraqueçaba.

Análise comparativa também foi realizada, comparando cenários turísticos similares ao apresentado em Guaraqueçaba, por exemplo, do Lagamar Paulista, para identificar lacunas e oportunidades de integração aos mesmos, inclusive pensando em uma estratégia regional ao invés de municipal, conforme aponta Mielke, Serra e Torres Bernier (2009). A escolha do Lagamar paulista se deu justificada pelo grau de consolidação do turismo nessa região, conforma aponta o plano de negócio participativo denominado "Modelo para o Ecoturismo com Base em Sistema Cooperativo no Litoral Norte do Estado do Paraná" (Projeto: PDA 054-MA), documento interno da cooperativa que foi disponibilizado para consulta. Ainda, roteiros relativamente consolidados, como os do Parque Nacional do Superagui, foram explorados em termos de potencial conexão dos pacotes com os demais atrativos isolados, como o surf e canoagem.

$\mathrm{Na}$ análise do contexto da evolução da cooperativa, o Plano de Negócio Participativo (PNP) foi consultado, pois é nele em que foi estruturada a forma de atuação da Cooperativa, buscando avaliar de maneira comparativa e propositiva a evolução do esperado versus o realizado e os fatores envolvidos nas possíveis 
divergências desse plano. Tal análise foi subsidiada por relatórios de projetos executados para fortalecimento da cooperativa, por documentos da própria cooperativa que pudessem ser compartilhados e por artigos científicos que abordassem o tema ou região. O alvo principal do PNP a ser explorado, na ótica do presente trabalho, foi o Comitê de Pacotes Turísticos (CPT), considerado como um dos elementos principais para o estabelecimento de parcerias efetivas.

Em termos do público alvo, o estudo foi desenvolvido pautado na interação com os atores envolvidos no contexto do turismo: Cooperativa, Agências de turismo, Público consumidor, ONGs e Poder público.

O desenvolvimento foi pautado em entrevistas com cada um dos atores citados acima, complementadas por levantamento de dados secundários. Com base nas entrevistas, foram elencados os principais fatores de sucesso e insucesso ao longo dos anos avaliados, estratégias inovadoras para acesso a novos mercados e maneiras de sensibilizar os mesmos atores sobre o papel das áreas protegidas no fornecimento de serviços para o turismo. Nesse processo 12 pessoas foram entrevistadas, consideradas relevantes para o processo investigado, elas membros da cooperativa, gestores de projetos em ONGs, diretores de agências de turismo, membros de associações, turistas e consultores de turismo envolvidos com atividades de estruturação da cooperativa em 2009.

Essa coleta de dados envolveu duas viagens a Guaraqueçaba, entre março e junho de 2016, e visitas in loco a agências de turismo, ONGS e pessoas envolvidas no processo.

\section{RESULTADOS E DISCUSSÃO}

Segundo análise realizada, a Cooperguará Ecotur foi criada em 2007 a partir de esforços conjuntos de ONGs que vêm atuando em Guaraqueçaba há muitos anos e o próprio desejo da comunidade em estruturar o turismo, atividade com potencial na região. O processo de estabelecimento das lideranças locais, e da adesão dos cooperados, foi algo muito natural. A partir dessa vontade e potencial revelado, alguns projetos foram desenvolvidos para estruturação e incubação da cooperativa, nos quais o 
recurso captado junto a fontes de financiamento públicas e privadas, foram destinados principalmente para capacitação dos cooperados em temas como governança, sustentabilidade, melhoria dos serviços, prestação de contas e finanças, associativismo entre outros.

No ano em que a cooperativa foi formalizada, 28 cooperados faziam parte da mesma, distribuídos em cinco núcleos quais sejam: Guaraqueçaba (sede), Tagaçaba, Antonina, Superaguí e Ilha das Peças. Os cooperados eram identificados por meio de um "selo" com a logomarca da cooperativa.

O grande desafio da estruturação de uma cooperativa desse porte, contou com uma série de ações estruturantes e de base para que isso ocorresse. Conforme já mencionado nesse trabalho, a fase inicial da cooperativa foi apoiada pela elaboração de um Plano de Negócio Participativo (PNP) - em 2005. Entre as principais diretrizes desse plano, pode-se citar a recomendação para o estabelecimento dos comitês de Produtos Turísticos e do Comitê Educativo, visando elaborar e dar visibilidade aos roteiros e promover a capacitação da cooperativa em temas considerados gargalos para o seu pleno desenvolvimento.

Um dos primeiros passos do comitê de produtos turísticos foi o estabelecimento, com a participação de algumas agências, dos roteiros que seriam comercializados, com base em seu apelo turístico e possibilidade dos cooperados realizarem os mesmos por conta de questões logísticas. A consolidação dessa meta resultou em onze atividades ofertadas pela cooperativa, com destaque para as áreas protegidas e espécies-bandeira. Nesse momento chama a atenção o fato de não ter sido criado nenhum roteiro focado em aventura, como canoagem, rapel e escalada potenciais que serão discutidos mais a frente nesse trabalho.

De fato, a pesquisa científica se revelou como um dos grandes geradores de demanda por atrativos ofertados pela cooperativa, em especial com o papagaio-da-cararoxa (ou chauá) (Amazona brasiliensis) que possui em Guaraqueçaba sua maior porção territorial no estado do Paraná, utilizando as ilhas para alimentação e dormitório (SHUNK et al., 2011). A revoada dos papagaios sem dúvida foi um roteiro bastante frequente da cooperativa, em que era possível observar os papagaios retornando aos locais de dormitório, pareados em casais, no fim da tarde, algo de muita beleza e simbolismo, por sua ligação com a cultura local. 
Por outro lado, o modo de vida caiçara também sempre esteve presente como um aspecto forte e de expressão da cooperativa. Os roteiros culturais foram desenhados de modo a ressaltar o contexto local, gastronomia, música e arte caiçara. O fandango dança típica local, é um atrativo que agrada muito aos turistas, pelo seu caráter simples integrador e único (observação pessoal, Thiago Piazzetta Valente). Relaciona-se muito bem com a famosa "cataia", bebida destilada preparada a partir da infusão das folhas de cataia (Pimenta pseudocaryophyllus). Nesse aspecto vale lembrar que a cataia tem sido alvo de pressão extrativista no Superagui e ações de pesquisa, manejo e conservação da espécie se tornam cada vez mais necessárias (DÁNGELIS, 2013).

Segundo dados fornecidos pela cooperativa, nos anos em que operou os roteiros em Guaraqueçaba, a cooperativa se envolveu principalmente com atividades que se relacionavam de alguma forma com as ONGs locais, que desenvolviam ações com parceiros nacionais e internacionais, realizavam eventos em Guaraqueçaba contratando os serviços da cooperativa na visita a atrativos, ou refeições, transporte etc.

A ausência de registro formal (banco de dados) das informações históricas dificultou a obtenção de dados ano a ano sobre o padrão de pacotes comercializados e outras estatísticas e tendências abordadas nesse estuco. Para isso as interlocuções feitas com representantes da Cooperaguará para discussão sobre os aspectos levantados nesse estudo, que focam principalmente na governança e acesso ao mercado, foram bastante ricas para atingir tal objetivo. $\mathrm{O}$ foco da discussão foi investigar, por meio de reflexões coletivas, os motivos que levaram a cooperativa a "esfriar" sua atuação em comparação com anos mais "favoráveis" e, principalmente, observar a implantação do plano de negócios e dos respectivos comitês previstos.

Adicionalmente detectou-se, por meio dos relatos, que a Cooperguará Ecotur contou com um robusto e amplo apoio técnico em sua fase de estruturação e buscou ao menos em princípio, estabelecer os principais comitês previstos. $\mathrm{O}$ comitê de pacotes turísticos foi instituído, mas operou por um tempo com a presença de agências e operadoras. Segundo a cooperativa, embora as agências tenham apoiado inclusive na formatação dos pacotes que seriam comercializados, essa contribuição ficou no plano das ideias já que as agências não geraram a demanda necessária, ou seja, as compras via agência foram muito poucas. 
Por outro lado, ao conversar com algumas agências ou demandadores de serviços da cooperativa, alegou-se que o distanciamento da Cooperaguará ocorreu principalmente à falta de compromisso de alguns cooperados, por exemplo, não cumprindo acordos e compromisso firmados. Por exemplo, o fato de deixar turistas esperando, ou não entregar o que era esperado em determinado pacote, gerou um desconforto que afetou as relações comerciais dessa natureza.

A má percepção das agências sobre a qualidade dos serviços pôde ser corroborada pela resposta de um dos quatro respondentes das agências, que conheciam a cooperativa, que citou que o fator qualidade seria um alvo de melhoria para a Cooperaguará. Os responsáveis pela cooperativa, de fato, assumiram que o Comitê de Qualidade poderia ter tido uma atuação mais ativa e consistente. A cultura local possui hábitos específicos que não devem ser qualificados ruins ou bons, mas que podem conflitar com os hábitos de turistas, por exemplo, o padrão de limpeza, tipo de roupa de cama utilizada, comida, entre outros. Embora esforços tenham sido feitos para promover a mudança ou ampliação da visão para uma perspectiva do turista, verificou-se que esse ponto ainda estava carecendo de ações intensas de capacitação.

Nesse sentido, o Comitê de Educação desempenharia um papel importante e estava previsto no plano de negócios justamente para atender as demandas dos demais comitês no momento que lacunas de conhecimento/atuação da comunidade fossem detectadas, como a questão de qualidade dos serviços citada. Contudo, citou-se que tal comitê demandaria investimentos pesados em capacitação de longo prazo, algo que não foi possível no âmbito das ações e governança da cooperativa.

Nesse cenário, não foi difícil para que as mesmas agências de turismo e as próprias ONGs que apoiaram na criação da cooperativa, começassem a buscar serviços "por fora" da cooperativa, que ficavam mais baratos, já que não tinham embutidos os $20 \%$ de taxa da cooperativa em seu custo. Isso acabou, segundo relatos, desarticulando os cooperados, em especial os das Ilhas do Superagui, que com um alto faturamento e demanda espontânea passaram a atuar sozinhos e sem repassar a taxa à cooperativa.

É simples pensar que $20 \%$ de todas as operações realizadas pelos cerca de 30 cooperados poderia, em pouco tempo, se reverter em um fundo, ou forma similar a esse, que garantiria várias ações que não frutificaram como a questão jurídica (pagamento de taxas), contabilidade e certamente a captação de novos recursos (fundo como 
seedmoney ${ }^{1}$ ). Associada a essa dificuldade de articulação, a baixa temporada foi detectada como fator crítico, pois a demanda muito baixa nos meses de inverno, trazia uma certa "inércia" ao sistema da região que a tornou muito vulnerável às externalidades citadas. Vários outros sistemas turísticos também enfrentaram tal situação, porém nesses casos, o faturamento dos meses de alta temporada, compensa muito a falta de movimentação nos meses de inverno.

Um dos alvos abordados nesse estudo foi justamente a falta de alternativas para a geração de novos negócios, inovação e atração de novos públicos, que pudessem, por exemplo, alavancar o turismo nos meses de inverno. Nesse momento, se pode apoiar rapidamente em alguns casos de sucesso, como a iniciativa da cooperativa dos produtores de ostra da região do Cabaraquara em Guaratuba-PR, Aguamar, que apoiadas pelo GIA-UFPR, desenvolveram o festival da ostra em paralelo à festa do Divino em julho. Tal estratégia possibilitou o escoamento de ostras nos meses do inverno, em que as condições ambientais proporcionam mais sabor e qualidade, garantindo comercialização em meses historicamente de escassez, associando o seu produto ao turismo em meses mais frios.

A discussão levantada de possibilitar que os atrativos atuais pudessem ser complementados por outros roteiros ainda não pensados traz alguns desafios, principalmente relacionados à forma que isso seria recebido pela comunidade local e também a cronologia de acoplamento dessas duas culturas - agências de fora e a comunidade local. Ainda assim considera-se interessante exercitar a habilidade em prospectar novos alvos. Algumas oportunidades seguem na sequência.

Embora o presente estudo esteja focado em análise de oportunidades de mercado, torna-se relevante descrever de forma sucinta a percepção de agências e usuários dos serviços sobre problemas de integração nas próprias comunidades/cooperados. Verificou-se haver indícios de que algumas lideranças importantes, especificamente na Ilha do Superagui, foram contrárias à estratégia e atuação da Cooperativa. Segundo eles, a forma que a cooperativa foi criada, com a participação de ONGs ambientalistas trazia um conceito que não era próprio da comunidade, gerando desconfiança.

\footnotetext{
${ }^{1}$ Seedmoney é um termo utilizado para descrever investimentos iniciais que visam alavancar recursos adicionais para ampliação de um novo negócio.
} 


\subsection{ANÁLISE DO ACESSO AO MERCADO}

Oito agências/operadoras responderam ao questionário, somente enviado àquelas que operavam turismo no Litoral do Paraná ou São Paulo. Desse universo amostral, de maneira geral detectou-se um padrão em que existiu elevado grau de conhecimento sobre a região (6 conhecendo atrativos), um grau médio de atuação na região (4 já haviam operado na região), um baixo nível de interação com a cooperativa local de turismo (dos 4 que conheciam a região 2 já haviam trabalhado em parceria) e pouco interesse em operar na região (4), salvo se houvessem algumas melhorias.

Das agências e operadoras que mencionaram conhecer a região (6 no total), todas apontaram como principais fortalezas as áreas protegidas (6 citações), parte delas citaram beleza cênica do local (4 citações) e cultura local caiçara (4 citações) como os três elementos mais fortes para o turismo na região (QUADRO 1), fato que corroborou o elevado grau de conservação da região e relação disso com seu potencial turístico. Nessa pergunta mais de uma opção era possível de ser selecionada. Ainda com boa relação ficou o turismo pedagógico, citado de fato como um potencial para a região por 3 dos entrevistados.

Um aspecto que se chamou a atenção, é que o componente menos citado foi o turismo de aventura, o que poderia indicar duas situações. Uma opção é que a atividade não seria a melhor alavanca para a região com base no perfil dos consumidores que as agências e operadoras normalmente atuam; ou pelo fato de desconhecerem boas possibilidades de práticas de atividades de aventura na região.

QUADRO 1 - POTENCIAIS ATRATIVOS CITADOS POR AGÊNCIAS E OPERADORAS
\begin{tabular}{|l|c|}
\hline \multicolumn{1}{|c|}{ Tipo de atividade } & $\mathbf{N}^{\mathbf{0}}$ de respostas \\
\hline Áreas Protegidas (RPPNs, Parque Nacional, ESEC) & 6 \\
\hline Contemplação - beleza cênica & 4 \\
\hline Cultura local caiçara & 3 \\
\hline Turismo pedagógico/científico/birdwatching & 1 \\
\hline Turismo de aventura (bike, canoa, trilha, rapel etc.) & \\
\hline FONTE: Pesquisa de campo, 2016. &
\end{tabular}

Se a segunda opção levantada, de que o potencial para o turismo de aventura não foi explorado de maneira estratégica em Guaraqueçaba, supostamente indicaria que novos serviços/negócios seriam possíveis. É fato que criar novos serviços é uma 
característica importante em projetos turísticos. Entre as diversas abordagens possíveis, Konu (2015) aponta o sucesso em um estudo de caso utilizando abordagem etnográfica e participação do consumidor no Desenvolvimento de Novos Serviços (DNS) para o turismo, ou seja, incluir os consumidores no desenho de roteiros e realizar análise de mercado pode ser relevante.

Um estudo etnográfico pode trazer à luz as potencialidades locais para novos produtos, e ao mesmo tempo investigar aspectos que possam ser introduzidos, mas que são similares. Por exemplo, a abordagem do stand-up-paddle $\left(\mathrm{SUP}^{2}\right)$ com a comunidade partiria de um ponto de conexão evidente, que é a proximidade e familiaridade dos moradores de Guaraqueçaba com o ambiente marinho e, por outro lado, a mesma familiaridade com aparatos operados com remo e na posição de pé em suas canoas, que é o mesmo princípio do SUP. Talvez existam outros elementos na cultura local que se aproximam dos que vêm de fora, mas que poderiam ser adaptados e transformados em oportunidades de novos negócios, fato que pôde ser corroborado em outros locais no Brasil com apelo cultural e paisagístico (HOLANDA; ARRUDA, 2004). O outro ponto destacado por esses autores, sobre o papel do consumidor, também é algo simples, porém, muito estratégico. O conceito de serviço (service concept) parte da premissa de envolvimento de vários stakeholders ${ }^{3}$ para a eficácia do planejamento de um novo serviço.

Outro elemento que se considerou interessante que poderia apoiar na mudança do cenário exposto, em que se percebeu haver falta de integração e assertividade para o DNS, poderiam ser os "imigrantes" que buscam por qualidade de vida em locais como Guaraqueçaba (amenity migrants), conforme citam Ruiz-Ballesteros e Caceres-Feria (2016). Esse novo habitante local traz consigo a "visão de fora" necessária na formatação de produtos mais alinhados com as necessidades urbanas, por exemplo. Esse ponto de contato pode ser muito positivo nessa nova concepção de turismo de base comunitária, mas pode levar ao mesmo cenário de outras diversas regiões do país, em locais que com a chegada desses migrantes munidos de visão de negócios, atuam em causa própria e não compartilham os benefícios com a comunidade.

\footnotetext{
${ }^{2}$ Stand-up-paddle (SUP) é um esporte praticado sobre uma prancha similar à de surf e um remo, que confere estabilidade ao praticante.

3 Stakeholders é um termo inglês que se refere às partes interessadas ou grupos de interesse em determinado processo.
} 
Por sua vez, o relativo estancamento das instituições e comunidades em relação às novas formas de conceber o turismo como negócio é um limitante. Holana (2016) aponta fatores contraditórios em relação ao que chama de "emprezarização" do turismo, uma vez que o TBC é um mecanismo que vai na contracorrente do mercado de turismo de massa. Porém, utilizar-se de ferramentas de um sistema para promover outro é o que caracteriza a inovação. De fato, esta tem sido alvo de interesse de muitos investidores. É possível citar, por exemplo, a plataforma Airbnb, que criou uma rede de hospedagem nas casas das pessoas, que ganhou mercado em todo mundo, justamente por dotar "de emoção" a estadia, valorizando a hospitalidade e as relações humanas no processo. A conexão de roteiros e formas de hospedagem em Guaraqueçaba seria um potencial novo produto, que envolveria público estrangeiro, apontado como estratégico nesse estudo.

Nessa linha, se poderia formular que, embora a cooperativa e as próprias agências tenham participado ativamente da elaboração de roteiros, talvez o pouco envolvimento do público consumidor, na perspectiva de realmente compreender o que motivaria esse público, possa ter sido uma falha. Nenhuma das potencialidades aqui levantadas como oportunidades de novos serviços fazia parte do menu de opções da cooperativa local.

A forte presença de elementos que poderiam alavancar o turismo é também revelada no interesse de algumas das agências em operar na região, mesmo que com algumas condicionantes. No âmbito das possíveis interpretações desse dado, infere-se que a proposição de melhorias ou condições para passar a operar na região, indica que haveria uma força de mercado, que eventualmente poderia converter-se em força política para que algumas das demandas fossem sanadas.

O fato é que muitas delas inclusive iam ao encontro das principais demandas dos moradores da região, como melhorias de acesso pelas estradas e mar, citadas por 4 dos 6 dos respondentes que conheciam a região (QUADRO 2). Por outro lado, há melhorias que dependem de fatores externos às políticas públicas como capacitação das comunidades para o turismo que nesse caso, poderiam ser executadas também por agentes privados, fato que novamente indica oportunidades de negócio. 
QUADRO 2 - MELHORIAS APONTADAS PARA QUE AS AGÊNCIAS POTENCIALMENTE OPERASSEM ROTEIROS NO LAGAMAR-PR

\begin{tabular}{|l|c|}
\hline \multicolumn{1}{|c|}{ Tipo de serviço } & $\mathbf{N}^{\mathbf{0}}$ de respostas \\
\hline Melhor acesso - estrada/barcos & 4 \\
\hline Capacitação da comunidade para o Turismo & 3 \\
\hline Qualidade dos serviços (hospedagem e alimentação) & 1 \\
\hline Maior diversidade/Oferta de roteiros & 1 \\
\hline Custo & 1 \\
\hline Melhores condições de negociação e ou preços e ou comissionamento & 1 \\
\hline
\end{tabular}

FONTE: Pesquisa de Campo, 2016.

Ainda sobre as melhorias necessárias para que algumas agências passassem a atuar na região, foram citados dois aspectos muito relevantes que é a questão da comunicação e do receptivo da comunidade, que de certa forma se relacionam com capacitação das comunidades para o turismo. Também foi citada a gestão inadequada do lixo em algumas comunidades, o que inibe a conexão e comercialização de pacotes para públicos exigentes, como estrangeiros que esperam alta performance na gestão do patrimônio natural e das áreas protegidas da região.

Essa falta de capacitação técnica evidenciada revelou que o comitê de educação formulado no plano de negócios não teve seu papel plenamente desenvolvido. Esse salto na qualificação dos cooperados para o turismo, também os tornaria aptos para participar em outra esfera estratégica para o turismo, que são as políticas públicas. A ausência de entidades permanentes que pudessem atuar nesse viés de educação para o turismo, poderia ter um papel importante na estruturação desse arranjo, como escolas de formação específicas para o turismo em Antonina ou Guaraqueçaba. Seria justificável, que em uma região com amplas possibilidades de posicionar o turismo como uma alavanca social, houvesse escola técnica ofertando cursos como formação de guias, assistentes administrativos, comunicação e design, gastronomia e outros que estivessem alinhados a essas necessidades de capacitação.

Por último, quando indagadas se públicos de outros estados poderiam se interessar pelos roteiros de Guaraqueçaba e o que os motivaria, todas as agências responderam haver potencial para atingir outros públicos, e que provavelmente o que faltaria para isso seria divulgação, uma estratégia robusta de comunicação. A beleza cênica e a autenticidade da cultura local foram colocadas como principal fator que atrairia os turistas. Analisando as percepções, considerou-se ter ficado evidente que a 
região possui beleza cênica e que não faltaria muito para que fosse alvo de roteiros focados nisso.

\subsection{ANÁLISE DOS PADRÕES DE GOVERNANÇA}

No âmbito da pesquisa sobre como outras iniciativas se organizavam e tomavam suas decisões, obteve-se a contribuição de cinco iniciativas de turismo em diversas regiões do Brasil. Desse universo, 4 das 5 das iniciativas constituía associação, cooperativa ou grupo organizado. Isso supostamente indicou que, embora a Cooperguará Ecotur tenha alegado que as taxas para a manutenção de pessoa jurídica nessa categoria tenha desmotivado sua manutenção de pessoa jurídica, outras iniciativas buscavam também esse tipo de organização que poderia ser viável, mesmo com dificuldades. A maior parte das iniciativas abordadas constituía grupos organizados e que possuíam fóruns específicos para tomada de decisão. O nível de maturidade de algumas inciativas poderia ser considerado alto, com ações há pelo menos 20 anos, conforme quadro 3:

QUADRO 3 - RESUMO DOS DADOS DAS 5 INICIATIVAS DE TURISMO QUE RESPONDERAM AO QUESTIONÁRIO SOBRE GOVERNANÇA

\begin{tabular}{|c|l|l|l|}
\hline Ano de início & $\begin{array}{c}\text { Constitui associação/ } \\
\text { cooperativa }\end{array}$ & \multicolumn{1}{|c|}{$\begin{array}{c}\text { Como toma as } \\
\text { decisões }\end{array}$} & \multicolumn{1}{|c|}{ Fase do Projeto } \\
\hline 1996 & Não & Conselho/anual & Operação \\
\hline 1998 & Cooperativa & Conselho/mensal & Operação \\
\hline 2007 & Cooperativa & Conselho/anual & Operação \\
\hline 2008 & $\begin{array}{l}\text { Rede de associações } \\
\text { comunitárias }\end{array}$ & Comitê/mensal & Operação \\
\hline 2012 & Cooperativa & Comitê/semanal & Implantação \\
\hline
\end{tabular}

Fonte: Pesquisa de campo, 2016.

Ainda que investigações sobre o tema da governança e forma como a comunidade toma suas decisões seja relevante do ponto de vista acadêmico, de forma mais ampla é possível ver sua relação com os processos, que direcionam especialmente as almejadas políticas públicas para o desenvolvimento do turismo, fatos que devem ser alvo de investigação profunda. Fazito, Scott e Russell (2012) indicaram que muito do 
discurso ideológico proposto para o desenvolvimento turístico a partir de uma lógica popular (bottom-up), na realidade é permeado por um complexo contexto político e econômico mais amplo, que faz com as decisões locais fiquem em uma espécie de "debates de micro-escala" que pouco afeta os fatores de risco que deveriam ser desafiados em uma escala maior. Isso fica evidente principalmente quando há um grande fator de pressão que se sobrepõe aos interesses locais, por exemplo, em áreas de mineração.

A partir dessa ótica em que os agentes públicos estão ofuscados quanto ao seu papel no processo, os investimentos na estruturação das necessidades básicas das cooperativas de turismo de base comunitária acabam tendo pouco impacto prático, o que retro-alimenta as dúvidas e desconfianças que rondam os projetos.

$\mathrm{Na}$ análise da quantidade e perfil dos cooperados, percebeu-se amplitude de variação entre as iniciativas de TBC abordadas. Entre os aspectos, investigados, o acesso ao mercado por meio de parcerias foi o que pareceu ser mais distinto entre as iniciativas, variando de 2 até 35 operadoras (QUADRO 4), ou seja, uma variação de cerca de 500\% no número de agências parceiras entre as cooperativas que responderam, embora não operassem na região de Guaraqueçaba. Esse número é certamente relevante, especialmente porque demonstra que as cooperativas mais antigas e que tomam suas decisões por meio de um conselho ou comitê mensal são as que têm em sua rede o maior número de cooperados e agências parceiras, demonstrando a viabilidade de tal rede de conexões.

Ou seja, a governança é de fato um fator relevante para que as iniciativas de TBC se estruturem e possam tomar suas decisões, mas uma governança compartilhada e na qual a comunidade é o principal ator. A governança sendo um termo mais utilizado no âmbito empresarial tem sido refutada e atribuída como um fator negativo e ligado à mercantilização do TBC, conforme preconiza Holana (2016). Isso de maneira nenhuma significa que o TBC deve acessar o mesmo mercado e estar na mesma "prateleira" dos demais destinos de massa. Porém, significa utilizar-se das mesmas ferramentas de acesso a esse mercado, para atingir um público diferenciado e latente. Porém, mais uma vez se acredita ser necessário apoiar-se na inovação e trazer elementos que funcionam em outros contextos e adaptá-los para o TBC e absorver aspectos positivos dessa relação. Isso não significa que o estabelecimento de mecanismos de governança irá se 
sobrepor aos interesses comunitários, pelo contrário, irá tornar os processos mais transparentes e compreensíveis. Nesse sentido, Castro e Pinto (2013) destacam a importância do processo decisório nas iniciativas de TBC e relacionam a importância da participação coletiva orientada para o benefício comum.

QUADRO 4 - PERFIL DOS COOPERADOS DAS INICIATIVAS INVESTIGADAS

\begin{tabular}{|c|c|c|c|c|}
\hline Associados & Iniciativa 01 & Iniciativa 02 & Iniciativa 03 & Iniciativa 04 \\
\hline Meios de hospedagem & 3 & 1 & 35 & 6 \\
\hline${\text { Alimentação - } \mathrm{n}^{\mathbf{0}}}^{\mathrm{N}}$ & 5 & 1 & 12 & 4 \\
\hline $\mathrm{N}^{\mathbf{o}}$ de Guias e condutores associados & 6 & 20 & 15 & 7 \\
\hline Meios de transporte & 6 & 10 & não há & 7 \\
\hline Agências e operadoras parceiras & 2 & 35 & 03 & 03 \\
\hline
\end{tabular}

FONTE: Pesquisa de Campo, 2016.

Outro aspecto relevante no contexto de acesso a mercado, que veio sendo discutido no presente estudo, é a forma de comercialização dos roteiros. A maior parte das inciativas de TBC acessadas comercializava seus roteiros primeiramente pela internet, seguido por agências/operadoras e feiras de turismo. Também foi citada a comercialização por meio de guia de turismo e comercialização no próprio local do empreendimento, no caso de roteiros em áreas protegidas que não faziam parte de associação.

Em termos comparativos com a Cooperguará Ecotur, vários dos entrevistados citaram que a ausência de um mecanismo efetivo de comercialização dos roteiros online, por meio de um website, certamente era um dos fatores limitantes para a ampliação do acesso ao mercado, que tem no mecanismo online um de seus principais aliados na comercialização de roteiros.

No que concerne ao perfil dos turistas (local de origem) e o que buscavam (principais atrativos ofertados) das cooperativas entrevistadas, pôde-se detectar o padrão de turistas oriundos do próprio local em raio de $100 \mathrm{~km}$ (4 respostas) do mesmo estado (3 respostas) possuindo contribuição maior que o dos estrangeiros (1 resposta), embora estes ultrapassassem os turistas de outros estados brasileiros. Ou seja, a percepção empírica de que se viaja pouco pelo Brasil e que alguns roteiros brasileiros atraem mais aos estrangeiros do que aos brasileiros pôde ser corroborada por essa pequena amostra feita pelo presente estudo junto às cooperativas entrevistadas. 
O fato da contribuição de estrangeiros ser maior do que a dos brasileiros traz importantes reflexões no contexto econômico e cultural, além de ser estratégica para investimentos na região do Lagamar ou outras que igualmente estejam buscando alavancar investimento e atrair novos públicos. Ou seja, parece ser mais estratégico investir no mercado de turismo internacional do que em estados vizinhos. Isso é uma premissa que necessitaria de um estudo específico para se obter respostas, mas certamente valeria o esforço de investigação.

Fora a questão de mercado levantada como principal desafio nesse estudo, um aspecto detectado nas entrevistas e diálogo com atores envolvidos com o contexto do turismo revelou um aspecto que também precisaria ser alvo de investigação e trabalho que foi o fator interpessoal e os relacionamentos entre os moradores de Guaraqueçaba. O relacionamento aberto e sincero é essencial para o estabelecimento de relações de confiança mútua. As lideranças identificadas e que assumiram o papel de "alavancar" a Cooperguará Ecotur, fizeram muito, e dedicaram muito e acabaram sendo alvo de críticas e desconfiança. Isso é muito negativo e precisaria de um trabalho de base relacional, inteligência emocional, assertividade e outras características relevantes para criar um padrão de relacionamento e comunicação mais estável e aberto nessas comunidades.

Nesse sentido, Burgos e Mertens (2015) destacam a importância da criação de vínculos compartilhados entre os diferentes membros de uma comunidade, para que passem a atuar em rede e isso possui uma significância nos processos de governança. Esses autores apontaram um estudo de caso em que a elevada proporção de membros conectados mediante relações de colaboração $(98,3 \%)$ ajudariam a sustentar o fluxo de informações e conhecimentos entre seus membros. Isso é muito relevante, pois o estabelecimento de redes de cooperação é um dos aspectos que não obteve sucesso na estruturação e evolução da Cooperaguará Ecotur e deve ser alvo de atenção nos próximos passos da iniciativa.

Outro aspecto é o modo com que a cooperativa se relacionava com clientes frequentes que comumente operavam seus roteiros por meio da cooperativa, mas que ao longo do tempo o deixaram de fazer, contratando serviços "por fora". Os resultados desse estudo demonstraram que a falta de diálogo aberto e sincero, visando identificar os motivos pelos quais esse tipo de prática estava ocorrendo, poderia ter corrigido essa 
falta de fidelidade de determinados clientes (entre eles as próprias ONGs locais e empresas).

\section{CONCLUSÃO E RECOMENDAÇÕES}

O presente estudo revelou que a forma como o Turismo de Base Comunitária foi estruturado em Guaraqueçaba estava possuindo algumas fragilidades. Primeiramente, pode-se afirmar, em relação ao padrão de governança adotado pela Cooperguará Ecotur, que o mesmo não foi efetivo em dois aspectos principais: o envolvimento sólido e constante das agências e operadoras na formatação de produtos turísticos e inovação dos mesmos (comitê de produtos turísticos); e a adoção de programas contínuos de capacitação e qualidade para os serviços turísticos (comitê de qualidade). Embora, a dificuldade de acesso à região tenha sido citada como um dos fatores de melhoria para alavancar o turismo na região, se os serviços ofertados tivessem melhor qualidade e apelo turístico, isso provavelmente ofuscaria qualquer dificuldade de acesso e geraria demanda.

Quanto às potencialidades de inovação, o "turismo de aventura", apesar de não ser o principal propulsor da atividade, revelou diversas potencialidades que poderiam ser exploradas em termos financeiros, conectando a novos mercados e gerando impacto positivo na comunidade e biodiversidade. $\mathrm{O}$ caso do stand-up paddle parece ter sinergia forte com a cultura caiçara, pelo fato de envolver remo e prancha, que poderia ser alvo de investimentos no futuro gerando demanda. Essa atividade trabalha de modo subjetivo e simbólico com uma característica presente na região adaptada a um cenário turístico de alto apelo estético e paisagístico, o que lhe confere potencial para conexão com o mercado de TBC.

Quanto aos aspectos que caracterizaram Guaraqueçaba no cenário vigente, os elementos da cultura caiçara são os que se destacaram e precisariam urgentemente ser valorizados e em alguns casos resgatados para que a proposta de modelo de turismo aqui apresentada seja viável. Sugere-se, portanto, que a valoração da cultura passe a ter o mesmo protagonismo da valoração ambiental, criando com isso a lógica de que, sem esses elementos, o turismo e desenvolvimento de inovação para novos mercados não será viável. 
Por último, o papel da Cooperguará Ecotur na transformação local, valorização da cultura caiçara e propulsor de uma forma nova de pensar o desenvolvimento na região deixou seu legado. Por isso que a retomada das ações na região poderia ser viável, desde que se perceba esse arranjo pré-existente, busque-se repactuar com os atores envolvidos e, principalmente, investimentos de longo prazo, dada a complexidade de se estabelecer um arranjo colaborativo ou comunitário efetivo. No entanto, um padrão sólido de governança que gere sustentabilidade, somente poderá ser construído, se a comunidade realmente estiver alinhada entre seus membros e com o surgimento de lideranças que possam conduzir o processo, reduzindo gradualmente a participação dos atores externos que os apóiam.

\section{REFERÊNCIAS}

AMEND, M. R. Avaliação da oferta e demanda turística na comunidade da Barra do Superagui/Paraná: subsídios para o desenvolvimento de um ecoturismo de base comunitária. 125 p. Dissertação de Mestrado (Ciências Agrárias). Universidade Federal do Paraná, Curitiba, 2001.

BRASIL. Plano de Desenvolvimento Integrado do Turismo Sustentável - PDITS, 2014. Disponível em:

<http://www.turismo.gov.br/sites/default/turismo/DPROD/PDITS/PARANA/PDTIS_LI TORAL_PARANAENSE.pdf >. Acesso em: 05/06/2017.

BURGOS, A.; MERTENS, F. A perspectiva relacional na gestão do turismo de base comunitária: o caso da Prainha do Canto Verde. Caderno Virtual de Turismo, Rio de Janeiro, v. 15 n. 1, p. 81-98, abr. 2015.

CASTRO, L. L. C.; PINTO, R. Sustentabilidade e turismo comunitário: aspectos teórico-conceituais. Caderno Virtual de Turismo, Rio de Janeiro, v. 13, n. 2, p. 213226, ago. 2013.

D'ANGELIS, A. S. R. Extrativismo e comercialização de Cataia na Ilha de Superagui. 89 p. Monografia (Ciências Biológicas). Universidade Federal do Paraná, Curitiba, 2013.

FAZITO, M.; SCOTT, M.; RUSSELL, P. The dynamics of tourism discourses and policy in Brazil. Annals of Tourism Research, v. 57, n. 1, p. 1-17, mar. 2016. 
HOLANA, L. A. Empresarização do turismo de base comunitária. Caderno Virtual de Turismo, v. 16, n. 2, p. 249-262, ago. 2016.

HOLANDA, S. M; ARRUDA, D. O. Calidad de los servicios ecoturísticos en áreas de protección ambiental el caso de Jericoacoara, Ceará, Brasil. Estudios y Perspectivas en Turismo, v. 13, p. 111-128, 2004.

KAUANO, E. E.; TOREZAN, J. M. D.; CARDOSO, F. C. G.; MARQUES, M. C. M. Landscape structure in the northern coast of Paraná state, a hotspot for the Brazilian Atlantic Forest conservation. Revista Árvore, Viçosa-MG, v. 36, n. 5, p. 961-970, set/out. 2012.

KONU, H. Developing a forest-based wellbeing tourism product together with customers - an ethnographic approach. Tourism Management, v. 49, p. 1-16, aug. 2015 .

MIELKE, E. J. C.; SERRA, M.; TORRES BERNIER, E. El modelo cooperativo de gobernanza para destinos turísticos de base cooperativa. Resultados de análisis de dos experiencias en Brasil. Cooperativismo \& Desarrollo, v. 93, n. 8, p. 1-18, 2009.

MIELKE, E. J. C. Desenvolvimento Turístico de Base Comunitária: Uma Abordagem Prática e Sustentável. São Paulo: Alinea, 2010.

PROJETO BAGAGEM. Semeando o Turismo Comunitário pelo Brasil. Série Turisol de Metodologias, 2010. Disponível em:

$<$ http://projetobagagem1.tempsite.ws/arquivos/livreto-projeto_bagagem-09-

parte1.pdf.> . Acesso em: 06/08/2017.

RUIZ-BALlESTEROS, E.; CACERES-FERIA, R. Community-building and amenity migration in community-based tourism development. An approach from southwest Spain. Tourism Management, issue c, v. 54, p. 513-523, 2016.

SCHUNCK, F.; SOMENZARI, M.; LUGARINI, C.; SOARES, E. S. (org.) Plano de Ação Nacional para a Conservação dos Papagaios da Mata Atlântica. Série Espécies ameaçadas $\mathbf{n}^{\mathbf{0}}$ 20. Centro Nacional de Pesquisa e Conservação de Aves Silvestres, Brasília, 2011.

SILVA, L. F. da; MANTOVANELI JÚNIOR, O.; SAMPAIO, C. A. C. Desenvolvimento turístico regional: Governança e territorialidade no caso da Oktoberfest Blumenau (Santa Catarina, Brasil). Turismo e Sociedade. Curitiba, v. 7, n. 1, p. 156-173, jan.2014.

SIMRPPN. Sistema informatizado de monitoria de RPPN. Disponível em <http://sistemas.icmbio.gov.br/simrppn>. Acesso em: 25/01/2017. 
YOUNG, C. E. F; DE BAKKER, L. B.; BUCKMANN, M. F. Y.; DE MATOS, C. H.; TAKAHASHI, L.; SILVA, M. L. B. Roteiro para valoração de benefícios econômicos e sociais de Unidades de Conservação. Curitiba: Fundação Grupo Boticário de Proteção à Natureza, 2015.

. Modelo para o Ecoturismo com base em sistema cooperativo no litoral norte do Estado do Paraná. Curitiba, 2005. Relatório técnico.

Recebido em: 15-09-2017.

Aprovado em: 15-10-2017. 


\section{APÊNDICES}

\section{I - Questionário semiaberto enviado às operadoras de turismo-pesquisa acesso ao mercado}

1. Conhece os atrativos/roteiros do Lagamar Paranense (Guaraqueçaba-PR)?

Sim

Não

2. Se sim, quais são os 3 aspectos que mais se destacam?

Contemplação - beleza cênica

Turismo pedagógico/científico/birdwatching

Turismo de aventura (bike, canoa, trilha, rapel etc.)

Cultura local caiçara

Áreas Protegidas (RPPNs, Parque Nacional etc.)

Tranquilidade do local

Outro (especifique)

Sim - quais?

3. Sua agência/operadora já desenvolveu atividades no Lagamar do Paraná?

Sim, no passado-

Motivos porque parou?

Não - motivos?

4. Caso nunca tenha operado nessa região, haveria interesse?

Sim

Não

Dependeria de algumas melhorias

5. Se parou de atuar, quais seriam as 3 principais melhorias necessárias para voltar a trabalhar na região?

Qualidade dos serviços (hospedagem e alimentação)

Maior diversidade/Oferta de roteiros

Melhor acesso - estrada/barcos

Custo

Capacitação da comunidade para o Turismo Melhores condições de negociação e ou preços e ou comissionamento

Outro (especifique)

Sim - Comente sua experiência

6. Sua agencia teve a experiência em trabalhar com a Cooperguará-Ecotur?

Não - motivos (não conhecia, não me recomendaram etc.)

7. Quais seriam os 3 aspectos da melhores estratégia para alavancar o turismo no Lagamar (Guaraqueçaba-PR)?

Divulgação

Estruturar cooperativa/associação

Melhorar acesso/estradas 
Investimento nas áreas protegidas (Parque Nacional, RPPNs)

Diversificar produtos

Outras opções

8. O que motivaria o público de outros estados a buscar o Lagamar do Paraná para a prática do turismo? 


\section{Questionário semiaberto enviado às iniciativas de turismo de base comunitária Lagamar Paraná - pesquisa acesso ao mercado}

Buscamos entender como a iniciativa de Turismo de Base Comunitária executada se estrutura em termos de organização, governança, perfil dos associados e roteiros.

Experiência Local

Turismo de Base Comunitária: Pesquisa de Acesso ao Mercado + Governança

1. Sobre o projeto:

Nome do Projeto

Ano de início

Constitui cooperativa, associação ou outra entidade organizada?

Frequência das reuniões da comunidade (semanal, mensal, etc)

Fase do Projeto

(implantação/sensibilização/capacitação/ comercialização dos serviços e ou produtos turísticos)

Outro (especifique)

2. Como o projeto toma suas decisões? Há um conselho ou comitê?

Sim, por meio de conselho e comitês específicos (educação, produtos turísticos,etc)

Não, não há comitê

3. No caso de associações/cooperativas, quantos associados e qual o perfil de cada um dos serviços:

Meios de hospedagem - $\mathrm{n}^{\mathrm{o}}$ de pousadas, hotéis ou casas receptivas associados

Alimentação - $\mathrm{n}^{\circ}$ restaurantes e bares associados

$\mathrm{N}^{\mathrm{o}}$ de Guias e condutores associados

Meios de transporte - $\mathrm{N}^{\mathrm{o}}$ de associados

Agências e operadoras parceiras

4. Meios de comercialização dos roteiros turísticos da comunidade

Agencias e operadoras

Internet - site da cooperativa/associação

Divulgação em feiras

Diretamente na comunidade

Outro (especifique)

5. O público consumidor dos principais roteiros é principalmente:

Local (até $100 \mathrm{~km}$ da comunidade)

Do mesmo estado do projeto

Outros estados

Estrangeiros

Roteiro 1

Roteiro 2

Roteiro 3 
6. Quais são os principais roteiros (passeios) comercializados?

7. O que as pessoas mais procuram, quais são os maiores motivadores para ir até o local?

Turismo de aventura (exemplo: rapel, rafting, trilha, escalada, surf)

Atrativos naturais (exemplo: praias, cachoeiras etc.)

Gastronomia (exemplo:pratos típicos)

Educação ambiental (pesquisa, aprendizagem)

Cultura (dança, artesanato)

Outro (especifique)

8. Na comunidade, algum proprietário de algum empreendimento comissiona quando é indicado por alguém ou alguma agencia?

Sim

Não

9. A contribuição do turismo em sua comunidade na renda das famílias que moram nela:

Forte mais de $50 \%$ da renda é obtida pelo turismo

Média - Entre 30-50\% de contribuição na renda

Baixa - até $30 \%$ de contribuição na renda

Qual é a principal ganho que o turismo trouxe para a comunidade?

Qual é o principal problema que o turismo trouxe para a comunidade?

Na sua opinião a comunidade já entende como funciona o negócio do turismo?

$\mathrm{Na}$ sua opinião, o turismo está ajudando a comunidade a se reunir mais, conversar mais sobre os outros problemas da comunidade?

10. Impactos do projeto: 